\title{
CONFLICT OF DOMESTIC AND PROFESSIONAL DUTIES AMONG LADY HEALTH WORKERS
}

\author{
Nazia Salah ud Din \\ PhD Scholar, Department of Social Work, \\ University of the Punjab \\ nazialcwu@gmail.com \\ Tahira Jabeen \\ Associate Professor, Department of Social Work, \\ University of the Punjab \\ tahira.dsw@pu.edu.pk \\ Yumna Meer \\ PhD Scholar, Department of Sociology, \\ Quaid-i-Azam University Islamabad \\ yumnameer@soc.qau.edu.pk
}

\begin{abstract}
Community Health Workers (CHWs) are helpful in linking the health services and different communities. They are referred as Lady Health Workers (LHWs) in Pakistan and are performing duty to provide reproductive and primary health care to communities. Lady health workers are facing many problems in their personal lives due to their professional duties. Present study is conducted to identify the problems faced by LHWs while providing services to the communities. Quantitative research methodology was employed to attain the objective and the social ecological model served as the theoretical framework to explain the data acquired. Systematic random sampling was used to draw the sample and interview schedule was used as tool of data collection. The findings of the study revealed that majority of the respondents were facing problems at domestic level because of their professional duties and it resulted in negatively affecting their personal health and family responsibilities. The study concluded that it is essential to focus and solve the problems of LHWs, so that they could be able to perform their duties more effectively.
\end{abstract}

Keywords: Lady Health Workers, Community Health Workers, Domestic problems, District Lahore

\section{INTRODUCTION}

Community Health Workers (CHWs) have evolved as critical members of the health-care team in low-income areas to deliver maternity and neonatal health care. (Jafree, ul Momina, Mahmood \& Khawar, 2020). In underdeveloped nations, CHWs are usually assigned tasks of providing preventative care (Haq, Iqbal \& Rahman, 2008). CHWs are quickly gaining recognition as an important part of the health workforce required to meet public health goals in developing nations (Kok, Kane, Tulloch, Ormel, Theobald, Dieleman \& de Koning, 2015). CHWs in poor nations are expected to perform exceptionally without receiving the necessary support to accomplish their jobs effectively (Jaskiewicz \& Tulenko, 2012). CHWs are an important connection between health care systems and a force for supporting healthy behavior in communities with limited resources (Perry \& Zulliger, 2012). Community health worker programs have proven to be one of the most effective strategies to improve primary healthcare access and quality while addressing human resource shortage (Liu, Sullivan, Khan, Sachs \& Singh, 2011). For the delivery of Primary Health Care (PHC) and the promotion of health, CHWs are critical members of the health team. CHWs are a diverse group of health professionals who work in communities outside of formal health institutions and have received some, but insufficient, training for the tough jobs they are expected to accomplish (Perry, Zulliger \& Rogers, 2014). The "Lady Health Worker" (LHW) of Pakistan's National Program for Family Planning and Primary Health Care meets the description of a Community health worker and is an important part of the country's health-care system (Haq, Iqbal \& Rahman, 2008). The Pakistan Lady 
Health Worker (LHW) program delivers reproductive health services at the doorstep of communities in countries where patriarchal norms inhibit women's access to health care (Mumtaz, Salway, Nykiforuk, Bhatti, Ataullahjan, \& Ayyalasomayajula, 2013).

In Pakistan, female health professionals (known as 'lady health workers') have formed the foundation of the system related to primary health care. (Khan, Khan \& Awan, 2009). Primary health care is a collection of health services designed to satisfy the requirements of people living in underdeveloped countries. Community health workers coordinate efforts between the health care facilities and the community during duty. Workers' confidence and the performance are dependent on their knowledge and communication abilities (Haq \& Hafeez, 2009). In response to gender-based impediments to women's access to services, Pakistan's government health system, like that of many other South Asian countries, has formed cadres of community-based health workers to provide health care services related to family planning. But, recruiting, educating, and retaining such female employees has proven problematic (Mumtaz, Salway, Waseem and Umer, 2003). The Pakistani government initiated Lady Health Workers Program in 1994. The Lady Health Worker plays a vital role in rendering health care services to common people. For the past many years, female health workers (also known as "Lady Health Workers") has been the mainstay of Pakistan's primary and reproductive health care system. Each of these women is in charge of 150-200 houses (about 1,000 individuals) in the communities they serve. They concentrate in reproductive health and family planning and provide primary health care. During the day, LHWs visit women in their homes; in the evening, community members visit local lady health worker's home (known as the "health house") for health counseling and basic care. In a society like Pakistan where direct interaction between men and women is discouraged, women in a role of lady health worker is extremely beneficial. When a Pakistani woman visits a male health care provider, she is expected to bring one of her male family members with her while LHWs have the benefit of being capable to visit females at home even when their husbands are at work (Khan, Saba, Anwar, Baseer \& Syed, 2006)

Over 1,00,000 women have been trained in Pakistan's Lady Health Workers program to provide community health care in remote areas. The program has not only revitalized the primary health-care system, but it has also aided in the eradication of gendered space divisions, which is a key barrier to women's access to fundamental services such as education and job possibilities. Though, it has a number of flaws that necessitate intervention by the government to ensure that the program's goals are met. The initiative offers chances on many levels: for the government, it serves as a critical pillar of support by creating network of primary health-care service providers; and for the women, it creates opportunities for their empowerment. In addition to their assigned activities, nearly all national and international community health projects rely heavily on the work of these female health workers (Khan, 2011).

In low-income nations, community health workers are frequently tasked with delivering primary health care. In rural Pakistan and urban slums, community workers recognized as LHWs (Lady Health Workers) provide basic health care at people's homes. Evaluations reveal that the program is a success but they also bring out variations in the service quality. It would be required to obtain the workers' viewpoints on their job responsibilities, obstacles, and levels of stress (Haq, Iqbal \& Rahman, 2008).

Existing studies were conducted through qualitative methods and focused only on the problems resulted due to lack of resources. Existing knowledge doesn't cover the domestic problems faced by LHWs. Most of the existing studies were evaluations of the Lady Health Workers (LHWs) program and did not focus on the issues faced by LHWs in the performance of their domestic duties. In the previous studies, qualitative methods were used with small sample size. In the available literature, a gap exists regarding the domestic issues faced by Lady Health Workers and a study was needed to cover this gap. The present study has been conducted to identify the domestic problems faced by Lady Health Workers due to their professional duties. So, the findings of the present study would help to know the domestic problems of the respondents because of their professional duties.

\section{REVIEW OF LITERATURE}

Afsar \& Younus (2005) conducted a qualitative study in Karachi, Pakistan to assess the strengths and weaknesses of the National Program for Family Planning and Primary Health Care (PHC) from the perspective of Lady Health Workers (LHWs). In collaboration with health workers, this study was 
conducted in order to offer recommendations for increasing LHWs' participation in PHC in Pakistan. According to the findings of the study, respondents reported financial incentives, flexible times and an opportunity to help humanity as reasons for joining the program. Although the curriculum was rated good, clinical training was despised by them due to the attitudes of the doctors. Basic understanding on common diseases, reproductive issues and basic clinical skills were indicated as additional training needs. The provision of services at the grassroots level and worker's acceptability in the community and reinforcement of health messaging was one of the program's major strengths. The contractual nature of the work, low salary, and payment inconsistency, no opportunity for advancement and lack of logistical support were reported as deficiency of the program. Necessary skills, professional development, and financial incentives should be offered to LHWs suggested by the study. The public should be informed about LHWs' allocated roles and obligations and the referral system for LHW clients has to be strengthened. The significance of LHWs in Pakistani PHC must be acknowledged and more progress must be made.

Afsar, Qureshi, Younus, Gulb and Mahmood (2003) conducted a quantitative study in Karachi, Pakistan to determine the proportion of patients who were referred and to identify the variables that led to the failed referral. The study found that 265 (76.4 percent) out of 347 patients were positive referral, while 82 (23.6 percent) were failed referrals. Ineffective referral was linked to having never visited the referral site before and not knowing who to meet at the referral location. Other major indicators included the patient's sickness duration, being not recognized at the referral place and failure of LHW to follow up. According to the survey, a considerable number of clients who are seen by LHWs are directed to a variety of health care facilities. Improved LHW management skills for minor medical issues would almost probably cut referrals in half. Efforts should also be made to improve communication and counselling skills of LHWs, which would help to decrease the number of unsuccessful referrals.

Bhutta, Memon, Soofi, Salat, Cousens and Martines (2008) conducted a study in rural Pakistan to look into the possibility of placing LHWs and Traditional Birth Attendants (TBAs) as community-based strategies to improve maternity care. The study found stillbirth and infant death rates in intervention villages were much lower than baseline. Lower stillbirth and newborn survival rates show that LHWs and TBAs may successfully implement a community and outreach program that leads to improved family home care practices, higher care-seeking behaviour, and increased use of trained care providers.

Haq, Iqbal and Rahman (2008) conducted a mixed method study in Rawalpindi, Pakistan to know the problems faced by LHWs. According to the study findings, significant occupational stress was discovered in about a quarter of the LHWs. Stress was associated to having a low socioeconomic status and long distance travel for work. Inconsistent medical supplies, inadequate stipends, lack of career structure and a lack of ability to connect effectively with families were the leading causes of job dissatisfaction among these professionals. For effective performance of community health workers, higher remuneration, better supply management and building communication skills should be an important part of their curriculum.

Haq and Hafeez (2009) conducted a qualitative study in Pakistan to document these workers' opinions of their requirements for knowledge and communications as well as image development through the media for continued education. The respondents reported that their communication abilities were "moderately adequate," but they wanted to improve. The respondents' knowledge of current health issues was insufficient and they expressed a desire to continue their education. The media helped to establish health workers' reputation as a trustworthy source of health information. A procedure should be established to allow health practitioners to refresh their knowledge, develop their communication skills, and increase their trustworthiness as educators.

According to Islam, Malik and Basaria (2002), the Ministry of Health's Lady Health Workers (LHWs) and Village-based Family Planning Workers (VBFPWs) from the Ministry of Population Welfare are expected to give services to the people and are often the only health care resource available, especially for women. Islam, Malik and Basaria (2002) conducted a study to comprehend the challenges that LHWs and VBFPWs face on daily basis. A contextual inquiry was undertaken followed by the focus group discussion with a diverse group of LHWs and VBFPWs. According to the findings, LHWs and VBFPWs encounter variety of issues that drastically limit their usefulness. 
To improve the country's primary health care services related to contraceptive use, these concerns must be identified and addressed.

Khan, Saba, Anwar, Baseer and Syed (2006) conducted a study in District Kohat, Pakistan to determine the strength of these services. It was a cross-sectional and descriptive study. Lady health workers with more than 2 years of experience were questioned about their understanding, attitudes, and talents in terms of job-related aspects. Home visits, family planning, prenatal care, infant care, immunization, growth measurement, recurrent infections, drugs, and referrals were among the variables. The study findings unveil that Lady Health Workers had a knowledge score of more than 36percent, an attitude score of more than 88 percent and a skill evaluation score of more than 86 percent. Due to poor health house administration, seven female health professionals produced unsatisfactory results. The use of contraceptives necessitated a significant development in skills. There was a lack of understanding about immunization schedules and $36 \%$ had insufficient knowledge about common drug doses. The study concluded that frequent lectures and training for LHWs should be held to keep their expertise up to date.

Khan, Amjad, Hafeez and Shareef (2012) conducted a mixed method study in Tehsil Gujar Khan, Punjab, Pakistan to assess social, anthropological, geographical and economic restrictions that Lady Health Workers (LHWs) experience in providing family planning services to their clients, as well as to analyse their approaches at system, community and individual levels. According to the findings of the study, religious hurdles accounted for 69 percent, sociocultural barriers 58 percent, transportation 54 percent, and communication and economic issues 25 percent as reported by the respondents. Female gender, insufficient experience and a lack of education were hurdles at the individual level. Increased workload, routine vaccination days, delayed supplies, supply shortages (especially injections), difficulty in referral of patients and a lack of appropriate incentives were all system-level obstacles.

Mumtaz, Salway, Waseem and Umer (2003) conducted a qualitative study to highlight a fact that female health providers often serve within the same gender structure that made their appointment possible is perhaps the most overlooked fact. The study employed qualitative approaches to gain a better understanding of the experiences of female community workers, particularly the gender-based constraints they confront. Women's gender-based cultural restrictions, abusive hierarchical management systems, disrespect from male employees, lack of knowledge of women's gender-based cultural boundaries, conflict between household and workplace responsibilities and limited infrastructural help were all highlighted as important concerns as per the findings of the study. The findings highlight the interconnectedness of women's professional and personal lives, as well as the interplay of class and gender inequality in determining women's work experiences. The findings of the study indicate the need of improving the organizational structure of health care services in order to facilitate female personnel to execute their duties more easily.

Yasin and Shahzad (2015) conducted a qualitative study in District Layyah, Pakistan to explore women's perceptions of community midwives (CMWs) and Lady Health Workers (LHWs) in comparison to traditional birth attendants (TBAs). According to the findings of the study, CMWs and LHWs were improperly deployed in their geographical area. Even if women were aware of their existence, they may lack trust in them. TBAs were the only inexpensive and accessible communitybased alternative for most women, thus they prefer to have their babies at home. At this time, raising community understanding of CMWs and LHWs' passion and commitment is critical in removing community reservations and getting their full confidence. The fundamental reasons for the current ineffective rural health program includes structural flaws, low pay, and a lack of official attention.

The literature review depicts that majority of prior studies were evaluations of the Lady Health Workers (LHWs) program and job-related concerns and did not cover the household problems faced by LHWs. The difficulties faced by LHWs in performing their household responsibilities because of their professional duties were not addressed in these studies.

\section{METHODOLOGY}

The study employed quantitative research methodology and cross-sectional survey design to collect the data. The locale of study was district Lahore and the respondents were Lady Health Workers (LHWs) providing health care services in the rural areas of Lahore. Systematic random sampling was used to draw the sample of 262 respondents from the list of all Lady Health Workers providing 
services in the rural areas of Lahore. As the geographical universe was so much scattered and it was not possible in the limited time and resources to collect data from the whole population, sampling was carried out. Interview schedule was used as a tool of data collection because respondents were not so much qualified and considering their limited proficiency, interview schedule was used to collect information. The objective of the study was to highlight the problems faced by Lady Health Workers in the performance of their domestic and professional duties. Social ecological model was used as theoretical framework to explain the data. According to social ecological model, an individual is affected by multiple environmental factors which are present in the surroundings of the individual, and the current study looked into the domestic issues that respondents faced as a result of their job responsibilities. Statistical test chi square was applied to check the association between different variables of the data obtained.

\section{RESULTS AND DISCUSSION}

Table 1 contains information regarding age group of the respondents. According to the data provided by 262 respondents, 45 percent were in the age group of 31-40 years. The age group of 27 percent respondents was 41-50, while 17 percent and 11 percent respondents were in the age group of 21-30 and 51-60 respectively. The average age of respondent was calculated as 39 years. Table 1 depicts the qualification level of the respondents. It shows that 44 percent respondents had a secondary level qualification while 40 percent respondents were having elementary level qualification. Intermediate level academic qualification was reported by 14 percent respondents, whereas only 5 percent respondents were graduates. Table 1 shows that out of 262 respondents, majority i.e. 76 percent were married. The widowed respondents were 11 percent and single were 7 percent, while 4 percent respondents were divorced and 2 percent were separated. The table 1 presents information regarding total number of family members of the respondents. It depicts that 58 percent respondents were having 5-7 family members while 19 percent were having 8-10 family members, 20 percent respondents were having 2-4 family members whereas few respondent's i.e. 3 percent reported to have 11-13 number of family members. Average family size was calculated as 6 members. Table 1 also depicts family system of the respondents. It reflects that out of 262 respondents, 64 percent were living in nuclear family system, while 31 percent were living in joint family system. Living in extended family system was reported by only 2 percent respondents.

Table 1: Demographic Profile

\begin{tabular}{|l|c|c|}
\hline Characteristics & Frequency \\
\hline Age of the Respondents (in years) & 45 & 17 \\
\hline $21-30$ & 118 & 45 \\
\hline $31-40$ & 70 & 27 \\
\hline $41-50$ & 29 & 11 \\
\hline $51-60$ & 106 & 40 \\
\hline Academic Qualification of Respondents & 44 \\
\hline Elementary & 114 & 14 \\
\hline Secondary & 37 & 02 \\
\hline Intermediate & 05 & 07 \\
\hline Graduation & 18 & 76 \\
\hline Marital Status of Respondents & 198 & 04 \\
\hline Single & 11 & 11 \\
\hline Married & 29 & 02 \\
\hline Divorced & 06 & 20 \\
\hline Widowed & 51 & 58 \\
\hline Separated & 154 & 19 \\
\hline Total Number of Family Members of the Respondents & \\
\hline $2-4$ & 50 & \\
\hline $5-7$ & \multicolumn{2}{|c|}{} \\
\hline $8-10$ &
\end{tabular}




\begin{tabular}{|l|c|c|}
\hline $11-13$ & 07 & 03 \\
\hline Family System of Respondents & 167 & 64 \\
\hline Nucleus & 82 & 31 \\
\hline Joint & 13 & 05 \\
\hline Extended & & \multicolumn{2}{|c|}{} \\
\hline
\end{tabular}

Table 2 contains information regarding the domestic problems faced by respondents due to their professional duties. The Table 2 reveals that there is a significant association between different types of domestic problems faced by respondents and their professional duties. According to the table, respondents reported that due to their professional duties they cannot give proper time to their families and they are unable to perform all household chores. They also revealed that they cannot perform their social obligations and cannot spare time for their own personal needs due to their professional responsibilities.

Table 2: Types of Problems Faced by Respondents due to Professional Duties

\begin{tabular}{|c|c|c|c|c|c|c|c|}
\hline Types of Domestic Problems & Yes & $\%$ & No & $\%$ & $\begin{array}{c}\text { Pearson } \\
\text { Chi- } \\
\text { square }\end{array}$ & $\mathrm{df}$ & p-value \\
\hline Cannot give proper time to family & 218 & 83 & 43 & 17 & \multirow{4}{*}{19.044} & \multirow{4}{*}{9} & \multirow{4}{*}{0.024} \\
\hline Cannot perform all household chores & 180 & 69 & 81 & 31 & & & \\
\hline $\begin{array}{l}\text { Cannot perform social obligations/ } \\
\text { commitments }\end{array}$ & 208 & 79 & 53 & 21 & & & \\
\hline $\begin{array}{l}\text { Cannot spare/allocate time for personal } \\
\text { needs }\end{array}$ & 189 & 72 & 72 & 28 & & & \\
\hline
\end{tabular}

Table 3 contains information regarding the consequences of domestic problems faced by respondents due to professional duties. Data in table 3 revealed that there is significant association between the consequences of domestic problems faced by the respondents and their professional duties. The respondents reported that they face domestic quarrels and their children get ignored because of their professional duties. The respondents also revealed that they had been cut off from social life and their personal health (physical/mental) suffers as a consequence of domestic problems faced by them due to their professional duties.

Table 3: Consequences of Domestic Problems due to Professional Duties

\begin{tabular}{|c|c|c|c|c|c|c|c|}
\hline Consequences of Domestic Problems & Yes & $\%$ & No & $\%$ & $\begin{array}{l}\text { Pearson } \\
\text { Chi- } \\
\text { square }\end{array}$ & $\mathrm{df}$ & p-value \\
\hline Domestic Quarrels & 76 & 29 & 185 & 71 & \multirow{4}{*}{147.831} & \multirow{4}{*}{9} & \multirow{4}{*}{0.000} \\
\hline Children ignored & 163 & 63 & 98 & 37 & & & \\
\hline Cut off from social life & 175 & 67 & 86 & 33 & & & \\
\hline $\begin{array}{l}\text { Personal health (physical/mental) } \\
\text { suffering }\end{array}$ & 206 & 79 & 55 & 21 & & & \\
\hline
\end{tabular}

\section{DISCUSSION}

Community Health Workers known as Lady Health Workers (LHWs) provide basic health care at the doorsteps in rural Pakistan and urban slums. The literature reviewed depicts that LHWs faced so many problems at professional level because of different factors. The present study focused on domestic problems faced by LHWs due to their professional duties and the consequences of these domestic problems in their personal lives. The study found that majority of the respondents were facing different types of domestic problems including time management for family and difficulty in performing household chores. According to the findings of the study, it was also revealed that respondents couldn't perform social obligations/ commitments and couldn't spare time for their own personal needs because of their professional duties. Domestic quarrels, children getting neglected, disturbed social life, and personal health sufferings were also discovered in the study as consequences 
of respondents' domestic problems caused by their professional responsibilities. Similar findings were also found by Mumtaz, Salway, Waseem, and Umer (2003) as their study revealed that respondents' main obstacles were inadequate understanding of women's cultural limitations due to their gender, contradiction between domestic and professional responsibilities and little infrastructural assistance. The current study findings emphasize the interconnection of women's public and private lives, as well as the interrelation of class and gender inequalities in the shaping of women's work practices. Another study by Closser, (2015) also found that polio work was a full-day activity that required LHWs to be away from their homes and children, affecting their responsibilities towards their own children.

\section{CONCLUSION}

According to the findings and discussion of the study, it is concluded that due to professional responsibilities, Lady Health Workers are subjected to a variety of domestic problems, which have negative implications in their personal lives. Due to work demands, they are unable to fulfill social obligations and managing time for their families. Other issues raised by respondents of this study included their inability to complete all domestic responsibilities and their inability to spare/allocate time for their personal needs. As a result, domestic strife arises, personal health (physical/mental) suffers, their children get neglected and they get isolated from social life. It is essential to focus on and solve the challenges of LHWs to enable them to be more effective in their responsibilities.

\section{RECOMMENDATIONS}

1. Based on the data, it is recommended that LHWs should only serve small number of households.

2. Extra duties and tasks outside of the community should be avoided, so that LHWs may able to balance professional and domestic responsibilities.

3. They should have fixed duty hours, so that they can accomplish their professional and domestic responsibilities more efficiently.

\section{REFERENCES}

Afsar, H. A., \& Younus, M. (2005). Recommendations to strengthen the role of lady health workers in the national program for family planning and primary health care in Pakistan: the health workers' perspective. Journal of Ayub Medical College, 17(1), 48.

Afsar, H. A., Qureshi, A. F., Younus, M., Gulb, A., \& Mahmood, A. (2003). Factors affecting unsuccessful referral by the lady health workers in Karachi, Pakistan. Journal-Pakistan Medical Association, 53(11), 521-528.

Bhutta, Z. A., Memon, Z. A., Soofi, S., Salat, M. S., Cousens, S., \& Martines, J. (2008). Implementing community-based perinatal care: results from a pilot study in rural Pakistan. Bulletin of the World Health Organization, 86, 452-459.

Closser, S. (2015). Pakistan's lady health worker labor movement and the moral economy of Heroism. Annals of Anthropological Practice, 39(1), 16-28.

Haq, Z., \& Hafeez, A. (2009). Knowledge and communication needs assessment of community health workers in a developing country: a qualitative study. Human resources for health, 7(1), 1-7.

Haq, Z., Iqbal, Z., \& Rahman, A. (2008). Job stress among community health workers: a multimethod study from Pakistan. International journal of mental health systems, 2(1), 1-6.

Islam, A., Malik, F. A., \& Basaria, S. (2002). Strengthening primary health care and family planning services in Pakistan: some critical issues. Journal of Pakistan Medical Association, 52(1).

Jafree, S. R., ul Momina, A., Mahmood, Q. K., \& Khawar, A. (2020). Satisfaction in Delivering Maternal and Neonatal Health Services During a Pandemic: Recommendations for Infection Preparedness and Response Protocols and Employee Support for Community Health Workers.

Jaskiewicz, W., \& Tulenko, K. (2012). Increasing community health worker productivity and effectiveness: a review of the influence of the work environment. Human resources for health, $10(1), 38$.

Khan, A. (2011). Lady health workers and social change in Pakistan. Economic and Political Weekly, 28-31. 
Khan, A. W., Amjad, C. M., Hafeez, A., \& Shareef, R. (2012). Perceived individual and community barriers in the provision of family planning services by lady health workers in Tehsil Gujar Khan. J Pak Med Assoc, 62(12), 1318-22.

Khan, M. H., Saba, N., Anwar, S., Baseer, N., \& Syed, S. (2006). Assessment of knowledge, attitude and skills of lady health workers. Gomal Journal of Medical Sciences, 4(2).

Khan, N. U., Khan, A. A., \& Awan, H. R. (2009). Women health workers: improving eye care in Pakistan. Community eye health, 22(70), 26.

Kok, M. C., Kane, S. S., Tulloch, O., Ormel, H., Theobald, S., Dieleman, M., \& de Koning, K. A. (2015). How does context influence performance of community health workers in low-and middle-income countries? Evidence from the literature. Health Research Policy and Systems, 13(1), 13.

Liu, A., Sullivan, S., Khan, M., Sachs, S., \& Singh, P. (2011). Community health workers in global health: scale and scalability. Mount Sinai Journal of Medicine: A Journal of Translational and Personalized Medicine, 78(3), 419-435.

Mumtaz, Z., Salway, S., Nykiforuk, C., Bhatti, A., Ataullahjan, A., \& Ayyalasomayajula, B. (2013). The role of social geography on Lady Health Workers' mobility and effectiveness in Pakistan. Social Science \& Medicine, 91, 48-57.

Mumtaz, Z., Salway, S., Waseem, M., \& Umer, N. (2003). Gender-based barriers to primary health care provision in Pakistan: the experience of female providers. Health policy and planning, 18(3), 261-269.

Perry, H., \& Zulliger, R. (2012). How effective are community health workers. An overview of current evidence with recommendations for strengthening community health worker programs to accelerate progress in achieving the health-related Millennium Development Goals. Baltimore: Johns Hopkins Bloomberg School of Public Health.

Perry, H. B., Zulliger, R., \& Rogers, M. M. (2014). Community health workers in low-, middle-, and high-income countries: an overview of their history, recent evolution, and current effectiveness. Annual review of public health, 35, 399-421.

Yasin, G., \& Shahzad, M. (2015). Challenges Faced by Healthcare Workers in Rural Punjab of Pakistan: A Qualitative Study. Asian Journal of Management Sciences \& Education, 4(2), 99109. 